\title{
Time-cost optimization using harmony search algorithm in construction projects
}

\author{
Optimización del costo del tiempo, utilizando el algoritmo de búsqueda de armonía en proyectos \\ de construcción
}

Mohammad Lemar Zalmai (Main Author)

Istanbul University-Cerrahpasa, Department of Civil Engineering

Istanbul, 34320 (Turkey)

lemar_zalmai07@hotmail.com

Cemil Akcay (Corresponding Author)

Istanbul University, Faculty of Architecture,

Istanbul, 34116 (Turkey)

cakcay@istanbul.edu.tr

\section{Ekrem Manisali}

Nisantasi University, Department of Civil Engineering

Istanbul, 34398 (Turkey)

ekmanisa@istanbul.edu.tr

Manuscript Code: 1153

Date of Acceptance/Reception: 05.07.2019/19.07.2018

DOI: $10.7764 /$ RDLC.18.2.226

\begin{abstract}
In construction projects, the relationship between project cost and duration, which is one of the main factors of the project, are considered the parameters decision-makers. When a construction schedule is planned by the planners, additional resources are allocated to shorten the project duration considering the completion time and cost of the activities so that the most suitable construction schedule is prepared by providing a tradeoff between project duration and total cost. In the case of time-cost trade-off problems, the total cost of the project is determined by summing each activities' cost by adding indirect costs. Moreover, total project duration is determined by obtaining total project duration after CPM (Critical Path Method) calculations. Obtaining optimum duration and costs is such a problematic issue with using conventional methods and common software packages. These techniques consider deterministic project values and include CPM calculations for fitness value calculation. Moreover, current studies defined alternatives as non-variable discrete values. However, construction projects are dynamic processes, and quantities are prone to be changed related to project size. In this study, time-cost trade-off optimization is performed by using harmony search method with introducing different implementation that can be more easily used for different projects. The model is implemented in a real construction project, and the conclusions are interpreted.
\end{abstract}

Keywords: Construction sector, CPM (Critical Path Method), multi-objective optimization, harmony search method, time-cost trade-off.

\section{Resumen}

En los proyectos de construcción, la relación entre el costo y la duración del proyecto, que es uno de los principales factores del proyecto, se consideran los parámetros que toman las decisiones. Cuando los planificadores planifican un cronograma de construcción, se asignan recursos adicionales para acortar la duración del proyecto considerando el tiempo de finalización y el costo de las actividades, de modo que el cronograma de construcción más adecuado se prepare al proporcionar un intercambio entre la duración del proyecto y el costo total. En el caso de problemas de compensación de tiempo y costo, el costo total del proyecto se determina sumando el costo de cada actividad al agregar los costos indirectos. Además, la duración total del proyecto se determina al obtener la duración total del proyecto después de los cálculos de CPM (Método de ruta crítica). Obtener una duración y costos óptimos es un problema tan problemático con el uso de métodos convencionales y paquetes de software comunes. Estas técnicas consideran los valores deterministas del proyecto e incluyen cálculos de CPM para el cálculo del valor de aptitud. Además, los estudios actuales definieron alternativas como valores discretos no variables. Sin embargo, los proyectos de construcción son procesos dinámicos, y las cantidades son propensas a cambiar en relación con el tamaño del proyecto. En este estudio, la optimización de la compensación de tiempo y costo se realiza utilizando el método de búsqueda de armonía con la introducción de diferentes implementaciones que se pueden usar más fácilmente para diferentes proyectos. El modelo se implementa en un proyecto de construcción real, y se interpretan las conclusiones.

Palabras clave: Sector de la construcción, CPM (Método de ruta crítica), optimización multiobjetivo, método de búsqueda de armonía, compromiso tiempo-costo.

Trade-offs frequently appear in the decision-making process in construction management. Duration and costs are considered as two primary variables, and in most cases, they are inversely related. So, in the scheduling phase, the timecost trade-off (TCTO) problem is appeared and can affect the project in various ways. For instance, in most contracts, the contractor has to satisfy various items in means of durations, quality and time. So, time-cost trade-off problems are 
considered as one of the great significant topics in project delivery and attention are paid by project managers. Time and cost as two critical objectives of construction project management are not independent but inversely related. Generally, time-cost trade-off appeared as a result of construction speeding up by changing crew-size, adding overtime and transition to other construction techniques (Feng, \& Liu, 1997; Hegazy, 1999). In general, determining time-cost trade-off is a difficult issue because it may depend on the project's inherent characteristics. While ongoing of the project, planners generally choose to crash critical activities to make project completed earlier to avoid delays, and also to gain opportunity costs by completing before finishing the project before the determined time. On the other hand, non-critical activities are chosen to be expanded to decrease in total cost (Siemens, 1971). Time-cost trade-off analysis is important parameters in the planning and control of construction projects; different resources and technologies play an active role in determining the duration and cost of the project, including appropriate workforce, equipment, and building methodologies. One of the most important concepts in today's construction sector is the effect of total finance when construction activities are done at different speeds. In this study, the optimal time-cost pairs of the project were obtained according to the HS model which was prepared to take the time and cost into consideration by determining the application methods and technologies of the activities in a project.

The reduction of the time and cost of construction projects is very important in today's market-oriented economy. The relationship between time and cost is called time-cost trade-off decisions, and this concept is being extensively explored in the construction management literature. The time-cost trade-off, as a crucial management tool, deals with the compromise between total cost and project duration, when it is not possible to plan a project within a certain time and exceeds one of the critical path method limitations.

In time-cost trade-off problems that can be solved by many different methods, the relationship between time and cost is first made as "continuous." However, due to the discrete values of the resources used, the problem is being used in practice as discrete time-cost trade-off problems by evaluating discrete data sets. As a classical method, a mixed integer programming is applied to many time-cost trade-offs applications. While classical methods to find the exact solution and heuristic methods to which the exact or approximate result is targeted, apply to time-cost trade-off problems (Sonmez, \& Bettemir, 2012). The most traditional form of time-cost relationship is expressed as linear. Kelley (1961), Siemens (1971), Salem \& Elmaghraby (1994), Hendrickson \& Au (1989), Tareghian \& Taheri (2006), and Chen \& Tsai (2011), apply linear approaches for time-cost problems. These methods can only optimize single-objective problems. However, if the optimization of time and cost is requested concurrently, these methods fail. The aim of TCTO is to find the best alternative solution by providing the optimal total duration and cost of the project. TCTO problem is very difficult to solve with traditional mathematical methods. Because time-cost trade-off problem includes so complicated formulation of mathematical structure and, thus it is very difficult to gain optimal solutions (De et al., 1997). Accordingly, the researchers try to find heuristic and metaheuristic methods to solve this problem and obtain the best solutions. The metaheuristic algorithms are outstanding methods in this field due to their flexible and adaptable structure. In this regard, metaheuristic methods have been developed to achieve the optimum or near-optimal result when classical methods are inadequate.

TСТО problem has been widely studied and many different algorithms have been suggested by many researchers in the literature. In the last decade, there are works where different methods have been used to solve the time-cost trade-off problem. Some of these studies related to TCTO problem solving with metaheuristic algorithms are as follows: Geem (2010a) applied a Harmony Search (HS) algorithm to solve time-cost trade-off problems. The objective is to minimize total cost, which includes direct and indirect cost. Also, Jian-Hong et al. (2017) propose time-cost trade-off of project based on the improved harmony search algorithm. Prascevic \& Prascevic (2014) applied the PSO method for solving time-cost optimization and developed a proper computer program for this purpose. Ashuri \& Tavakolan (2015) proposed the Pareto front optimization of resources together with the time and cost and presented a Shuffled Frog Leaping Algorithm. Aminbakhsh \& Sonmez (2016) presented discrete particle swarm optimization method for the largescale discrete time-cost trade-off problem. He, He, Liu, \& Wang (2017) proposed Variable Neighbourhood Search and Tabu Search for TCTO problem to minimize the maximal cash flow gap. Tran \& Long (2018) presented Project scheduling with time, cost and risk trade-off using adaptive multiple objective differential evolution. They applied an algorithm named as adaptive multiple objective differential evolution (AMODE) for producing optimized schedules considering time, cost and risk simultaneously. Albayrak \& Ozdemir (2018) proposed a novel hybrid method based on FA and PSO for time-cost trade-off in construction. In this method, the problem is modeled with various execution modes to select the optimal one for each activity.

In this study, we applied HS on solving TCTO problem on a real construction project. In the present study, the techniques and alternative applications for excavation and foundation activities of a construction project were investigated. In this respect, similar work items were drawn for each activity, based on unit price analysis. Later on, from the relevant work items of their activities, it was aimed to reach the most suitable time-cost pairs (Pareto solution set) of the project with 
HS method. Because alternative solutions to the problem are not ignored, the most appropriate time-cost pair can be selected from the proposed solution set according to the duration or cost constraint of the project. Therefore, it is emphasized that the implementation project should present the Pareto results in detail, taking into account the different applications of the activities in a project, and emphasized that alternative solutions should not be ignored. Each alternative solution includes different construction production technique. In Pareto analysis, there may be numerous alternatives can be obtained instead of only one optimum solution. So that different alternative production techniques are not neglected in order to optimize both project duration and cost.

\section{Description of the problem}

In literature, only generic applications were given. For instance, discrete time-cost variables have been used and analyzed. However, in the construction sector, the variables are project-dependent and can depend on project-size and economical conditions. In order to apply to the construction sector, real projects data needs to be used and applied in a more realistic style. For instance, we used quantities and unit costs directly to display the result in a more practical way. Rather than a case study, this paper applies time-cost trade-off methodology in a more realistic way. The HS algorithm can solve various types of problem very easily and effectively because complex calculations are not required. The HS can use discrete, continuous relationships and linear and nonlinear functions can be implemented in it (Peraza, 2015). Different kinds of algorithms can be merged with HS. Such as, HS has "stochastic-derivative" which makes this algorithm works well for combinatorial optimization problem (Geem, 2008). Thus, this study used because of its simplicity and versatility. Due to its simplicity and versatility, the HS algorithm is convenient for this study.

State of the Art Review on optimization and harmony search algorithm

\section{Categorization of optimization algorithms}

Optimization problems are generally considered as deterministic and stochastic in two main categories (Table 1). In the deterministic approach, while solutions are made by classical methods taking into account the known parameters, the variables that may occur in the design are not considered, whereas the variables in the stochastic approach are taken into account. Current techniques for solving the construction time-cost concession problem; heuristic scanning and mathematical programming.

\begin{tabular}{ll}
\multicolumn{2}{l}{ Table 1. Categorization of optimization algorithms Source: Yang (2010). } \\
\hline Deterministic & Stochastic \\
\hline Linear programming & Heuristic \\
Non-linear programming & Metaheuristic ${ }^{*}$ \\
Gradient-based & \\
Free of gradient & \\
\hline "Population-based, Trajectory-based.
\end{tabular}

In the mathematical programming method, time-cost trade-off problems are transformed into mathematical models and solved by linear programming, integer programming or dynamic programming methods. The mathematical programming problem consists of optimizing a goal function under certain constraints.

Heuristic methods are algorithms based on natural phenomena to accomplish any purpose or goal, and these algorithms generally provide good solutions but do not consider optimality. For this reason, the exact solution is not obtained because the heuristic algorithms have the convergence feature, so a solution is obtained near the exact solution.

Metaheuristic methods aim to combine basic heuristic methods that will enable the search for solution space efficiently. In this respect, these methods are general purpose heuristics designed to guide probing-specific intuitions to perform searches in regions of high-quality solutions of search space (Stützle, \& Dorigo, 2004). Top-heuristic algorithms; is a decision mechanism that works on heuristic algorithms. When three different methods are used for a problem, and each of these methods is predicted to be heuristic algorithms with advantages for different purposes, it is decided by the metaheuristic algorithm that the heuristic methods are selected.

The most preferred and known heuristic methods in engineering problems; Genetic algorithm (GA), Particle swarm optimization (PSO), Ant colony optimization (ACO), Harmony search (HS), Artificial bee colony (ABC), Simulated annealing (SA) and Firefly algorithms (FA). Currently, more than one method has been developed for the solution and is optimized according to the problems. However, the possibility of choosing between more than one solution methods 
for a problem is achieved by using the metaheuristic method. The most heuristic algorithms on which statistical data are based are often run with the most successful ones selected from among the algorithms.

\section{Harmony search method}

Harmony search (HS) is a meta-heuristic algorithm developed by Geem et al. (2001) which is inspired by the natural musical performance process that occurs when a musician searches for a better state of harmony. The algorithm is inspired by melodic harmony that objects to find convenient sounds to match with the musical clef. There are different musicians and instruments that sound at the same time. Similar to the improvisation process of musicians to find the convenient tone, the algorithm finds optimum trials with meta-heuristic search technique.

Harmony Search (HS) is a population-based meta-heuristic algorithm which has gained great results in the field of combinatorial optimization (Geem, 2001). As HS is a population-based algorithm, it maintains a set of solutions in Harmony Memory (HM). At every iteration, an estimation of the optimal solution is obtained by a set of optimization parameters which applies to the HM to produce a new harmony vector every time. Figure 1 illustrates the flow diagram of the HS algorithm, which can be summarized in four steps: (I) initialization of the HM; (II) improvisation of a new harmony; (III) inclusion of the newly generated harmony in the HM provided that its fitness improves the worst fitness value in the previous HM; and (IV) returning to step (II) until a termination criteria (e.g. maximum number of iterations or fitness stall) is satisfied.

The metaheuristic algorithms have a strong dependency on the shape of the solution space drawn by the metric function. Therefore, we cannot say to any meta-heuristic algorithm that is better than others according to convergence and behavior in a general manner. But instead, needs to be evaluated by focusing on a certain problem with its constraints and mathematical formulation. Thus, even though a globally optimal algorithm that shows the best performance in all optimization schemes does not exist in line with the statements of the so-called No Free Lunch Theorem (Wolpert \& Macready, 1997), the HS algorithm still has demonstrated in practice a great potential and efficiency in a wide range of real applications compare to other meta-heuristic methods. HS has a similar structure to other existing population-based metaheuristic algorithms. But HS contains some significant features that make it widely used in the literature. HS generate a new vector after considering all existing vectors instead of considering only two (parents) as in the genetic algorithm, and it does not need to initial values of decision variables (Geem et al., 2001). Also, instead of a gradient search, the HS algorithm uses a stochastic random search that is based on the harmony memory considering rate (HMCR) and the pitch adjusting rate (PAR) so it does not need to any derivative information (Geem, 2010b). These features help HS in increasing flexibility and in finding better solutions, so it widely used in the literature.

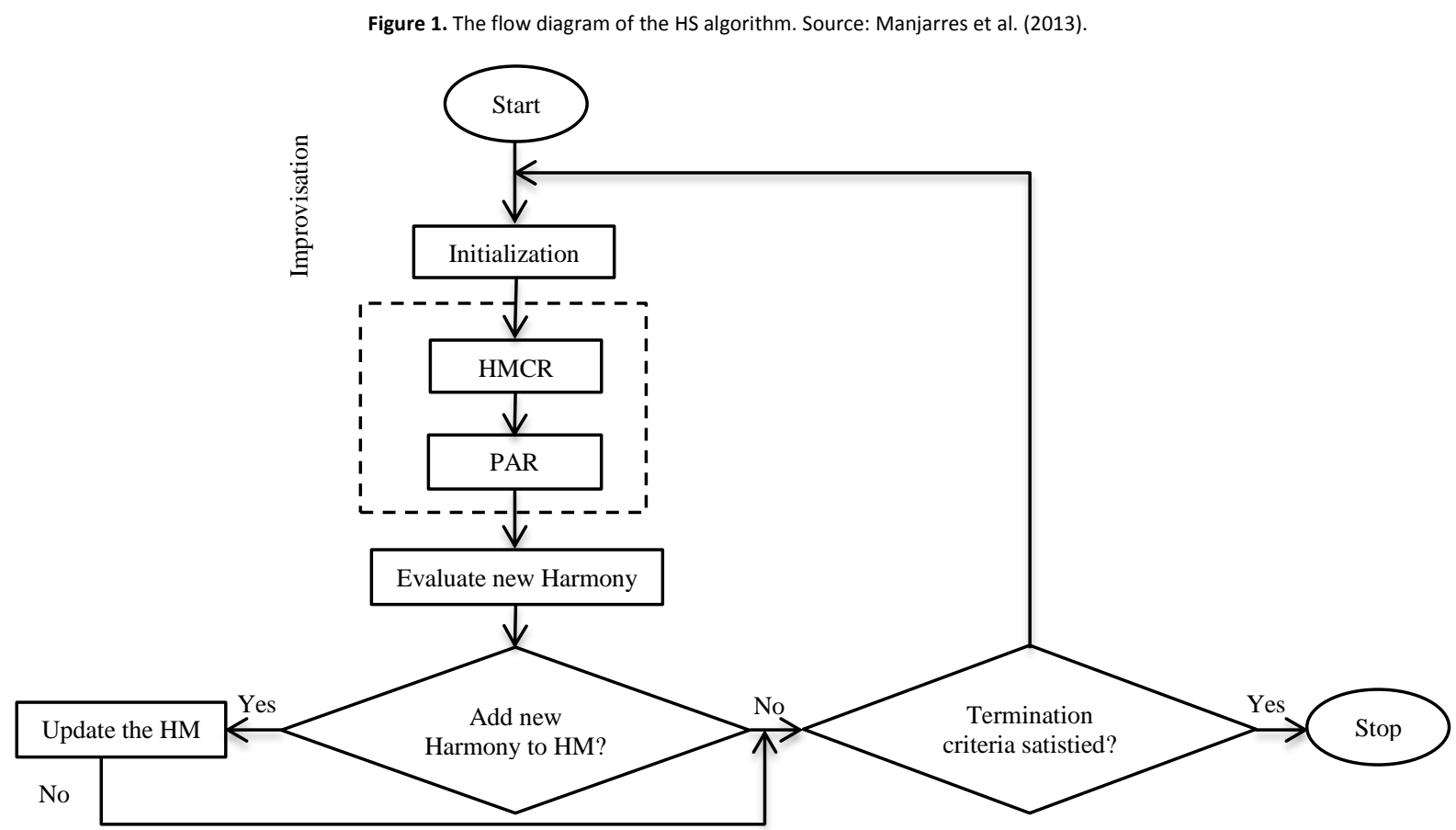

The main advantages of the HS algorithm are its simplicity and versatility (Lee \& Geem, 2005). Geem (2008) states that HS algorithms is a versatile methodology that has been applied for various engineering applications. Comparing to genetic algorithm memory usage is an advantage of Harmony search algorithm (Lee \& Geem, 2005). There various 
studies that based on comparing meta-heuristic algorithms. Peraza, Valdez \& Castillo (2015) compared HS and GA algorithms on solving benchmark problems and indicated that HS method dominates GA by finding optimal solutions. Lee \& Geem (2005) tested HS on various structural benchmark problems and compared the algorithm with deterministic mathematical techniques and genetic algorithms, and concluded that HS method shows better results than these two group of algorithms.

Compared to other meta-heuristics in the literature, the HS algorithm demands less mathematical requirements and can be easily adapted for solving diverse kinds of engineering optimization problems. (Mahdavi et al., 2007; Orman, \& Mahdavi, 2008). The method is applied to the various problems such as vehicle locomotion, pipeline design; application of multi-user detection problem, application of access point location problem (Geem et al., 2005; Gil et al., 2009).

A HS meta-heuristic algorithm was conceptualized using the musical process of searching for a perfect state of harmony (Geem \& Kim, 2001). Musical performances search to find agreeable harmony as defined by an aesthetic standard, just as the optimization process seeks to find a perfect solution as determined by an objective function.

In Figure 2(a), shows the details of the analogy between the method developed for capturing appropriate harmony in music (music improvisation) and the processes performed to achieve an optimum solution in engineering problems. Harmony search, a heuristic algorithm produced by musician improvisation, is a musical metaheuristic optimization method. The method is based on the principle of obtaining the best melody in terms of harmony with notes played by orchestra musicians. In the method, the orchestra can be obtained by optimizing the result, the objective function, and the best solution approach, while the most aesthetic melody can be obtained by playing all orchestral elements in harmony with each other.

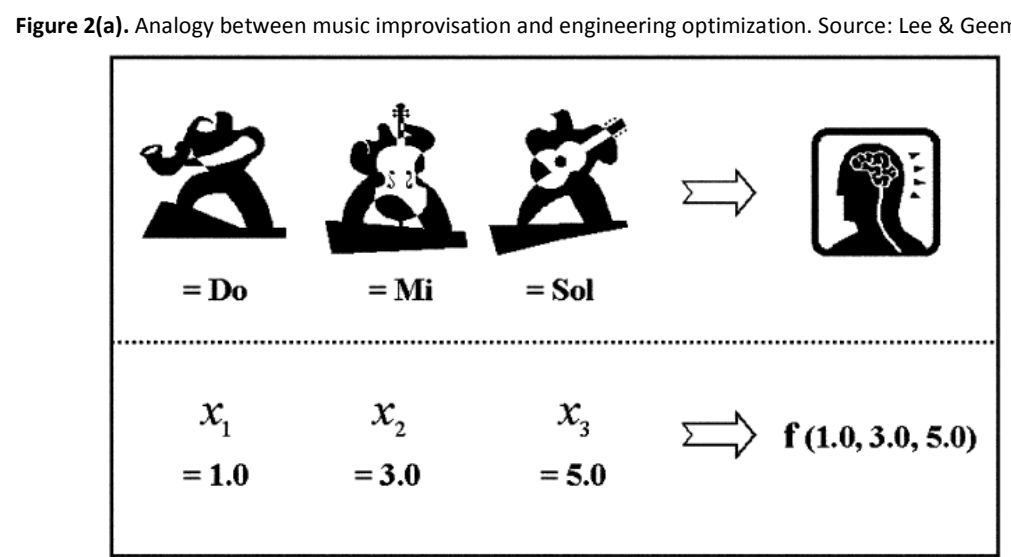

Figure 2(b). The simulation between music improvement and engineering optimization. Source: Lee \& Geem (2005).

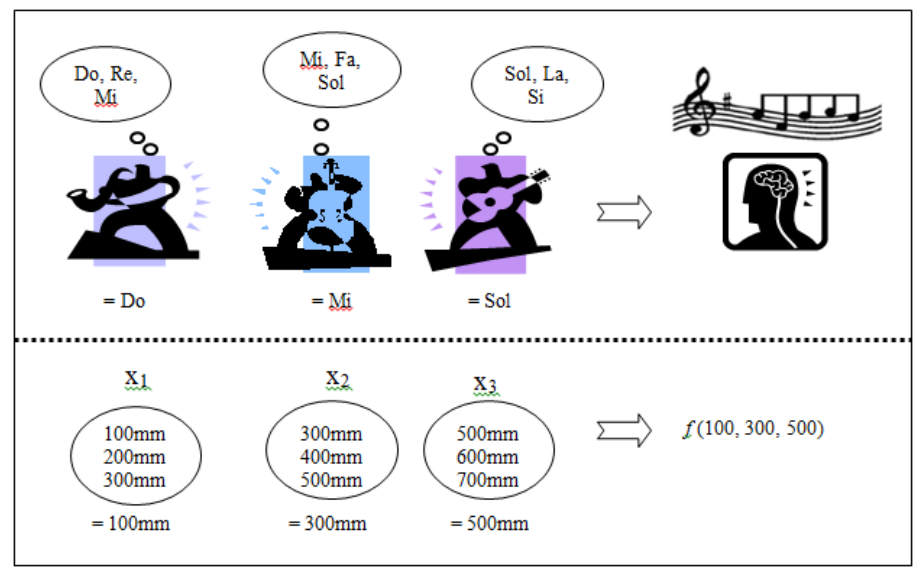

As shown in Figure 2(b), the options (do, mi and sol) were selected from the instruments in response to which question, respectively, which should be subtracted from each of the three available instruments in order to create a proper harmony. Similarly, the answer to the question of which values of the variables should be chosen to minimize a function bound to three variables is given as $f(100,300,500)$. While the aesthetic qualities of notes and tones played with different instruments are improved by practicing in music studies, this improvement is realized by successive iterations in the function solution. 
The HS process consists of five-steps:

Step 1. Defining the problem and solution parameters: The objective function and variables of the function, which will be used in the solution to the problem, are as defined as follows:

$$
\begin{aligned}
& \text { Objective function } \\
& \text { Decision variables, } \quad x_{i} \in X_{i}, \quad i=1,2, \ldots, N
\end{aligned}
$$

In this context, $f(x)$ refers to the objective function; $x_{i}$ refers to the variables, $X_{i}$ refers to the range; and refers to the number of variables in the function. Parameters such as harmony memory size (HMS) which harmony search method requires in order to solve an optimization problem, harmony memory considering rate (HMCR), and a maximum number of the iteration are defined at this stage.

Step 2. Generation of Harmony Memory: Harmony memory is where all solution vectors and the values the objective function obtains as a result of each iteration are stored. This matrix called harmony memory is full of randomly produced variable values, then the objective function's values corresponding to these produced values are calculated.

Harmony memory matrix:

$\left[\begin{array}{ccccc}\mathrm{x}_{1}^{1} & \mathrm{x}_{2}^{1} & \cdots & \mathrm{x}_{\mathrm{N}-1}^{1} & \mathrm{x}_{\mathrm{N}}^{1} \\ \mathrm{x}_{1}^{2} & \mathrm{x}_{2}^{2} & \cdots & \mathrm{x}_{\mathrm{N}-1}^{2} & \mathrm{x}_{\mathrm{N}}^{1} \\ \vdots & \vdots & \ddots & \vdots & \vdots \\ \mathrm{x}_{1}^{\mathrm{HMS}-1} & \mathrm{x}_{2}^{\mathrm{H}} & \cdots & \mathrm{x}_{\mathrm{N}-1}^{\mathrm{HMS}-1} & \mathrm{x}_{\mathrm{N}}^{\mathrm{HMS}-1} \\ \mathrm{x}_{1}^{\mathrm{HMS}} & \mathrm{x}_{2}^{\mathrm{HMS}} & \cdots & \mathrm{x}_{\mathrm{N}-1}^{\mathrm{HMS}} & \mathrm{x}_{\mathrm{N}}^{\mathrm{HMS}}\end{array}\right] \Rightarrow\left[\begin{array}{c}\mathrm{f}\left(\mathrm{x}^{1}\right) \\ \mathrm{f}\left(\mathrm{x}^{2}\right) \\ \vdots \\ \mathrm{f}\left(\mathrm{x}^{\mathrm{HMS}-1}\right) \\ \mathrm{f}\left(\mathrm{x}^{\mathrm{HMS}}\right)\end{array}\right]$

Step 3. Generation of new harmony: In this step, a new harmony is established through using the values in the harmony memory. The elements of the new harmony vector are generated according to the possibility of HMCR by either using the elements of the harmony memory or allocating a random value to $X$ range as applied in the second step. For this purpose, firstly a random number is selected between 0 and 1 values. If the randomly produced number corresponds to the HMCR possibility, which has a value between 0 and 1, the new vector element can be picked among the elements in the harmony memory. If the randomly produced number does not correspond to the HMCR possibility, the new vector element is randomly chosen among the variables in the range, and not picked from the harmony memory.

$x_{i}{ }^{\prime}=\left\{\begin{array}{cc}x_{i}{ }^{\prime} \in\left\{x_{i}^{1}, x_{i}^{2}, x_{i}^{3}, \ldots, x_{i}^{H M S}\right\} & \text { HMCR possibility } \\ x_{i}{ }^{\prime} \in X_{i} & (1-\text { HMCR }) \text { possibility }\end{array}\right\} \quad i=1,2, \ldots, N$

Step 4. Update of Harmony Memory: At this stage, primarily the objective function is calculated according to the value of the newly generated solution vector. Afterward, this value is compared to the objective function value of the solution vectors in the memory. If the objective function value of the newly generated solution vector is better than the values of the objective function, the newly established harmony solution vector replaces the harmony vector, which has the worst objective function value, and the worst solution vector is erased from the memory. In this way, better solution vectors are stored in the harmony memory.

Step 5. Repetition of the 3rd and fourth steps until termination criterion: At this stage, the termination criterion, which is defined for the problem, is checked. If this criterion is satisfied, the resolution ends, and the best vector found in the harmony memory is considered the final solution. If this criterion is not met, the 3rd and fourth steps are repeated.

\section{Methodology}

The general parameters used in time-cost trade-off optimization formulations are discussed in this section. In this scope, it is performed to evaluate the daily outputs for activities in the construction of a building were evaluated according to Harmony Search Method; and then it is developed to the most convenient solution model over its performance elements including duration and cost. To this end, the project duration and cost were calculated using Eq. 5; and the most convenient solutions were attempted to be obtained through the HS model.

$\mathrm{Z}=\sum_{\mathrm{i}=1}^{\mathrm{n}} \sum_{\mathrm{k} \in \mathrm{Ki}}\left(\mathrm{Q}_{\mathrm{i}} * \mathrm{C}_{\mathrm{i}}^{\mathrm{k}}\right)+\mathrm{C} * \mathrm{EF}_{\mathrm{n}+1}$
$\mathrm{EF}_{\mathrm{i}}=\mathrm{ES}_{\mathrm{i}}+\sum_{\mathrm{k} \in \mathrm{K}_{\mathrm{i}}} \mathrm{t}_{\mathrm{i}}^{\mathrm{k}} \quad i=0, \ldots \ldots \ldots \ldots, \mathrm{n}+1$ 


$$
\begin{aligned}
& \mathrm{ES}_{\mathrm{j}}=\max _{\mathrm{i} \in \mathrm{p}_{\mathrm{j}}}\left\{\mathrm{EF}_{\mathrm{i}}\right\} \quad j=1, \ldots \ldots \ldots \ldots, \mathrm{n}+1 \\
& \mathrm{ES}_{0}=0
\end{aligned}
$$

Here, $Z$ refers to the total cost of the project; $n$ refers to the number of activity in the project; $Q_{i}$ refers to the amount of $i^{\text {th }}$ activity; $C_{i}^{k}$ means the direct unit cost of $k$ option of $i^{\text {th }}$ activity; Ki refers to $k$ option set of $i^{\text {th }}$ activity; $C$ means the indirect cost of the project; $E F_{i}$ refers to the shortest time the activity could be completed; and $E S_{i}$; refers to the earliest data the activity could start. $t_{i}^{k}$ is the activity duration of $k$ option for $i$ activity and $P_{j}$ is the activity set right before $j^{\text {th }}$ activity. The steps of the HS model developed for the problem, are demonstrated in the flow chart in Figure 3.

Figure 3. Flow diagram of the proposed solution method. Source: Zalmai (2015).

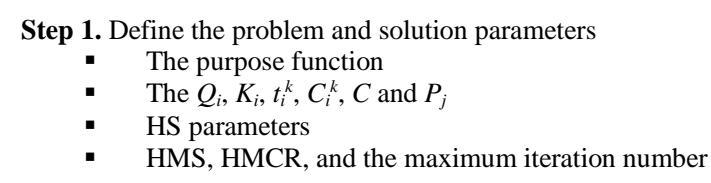

Step 2. Randomly filling the harmony memory using the values, which may be given to the activity options

Calculate the Project-duration and -cost for solution vector up to HMS

Step 3. Prepare a new harmony solution vector

(If HMCR criterion is met, the new solution vector is randomly selected among the elements in the harmony memory. If HMCR criterion is not met, it is randomly created within the range of the activity options.)

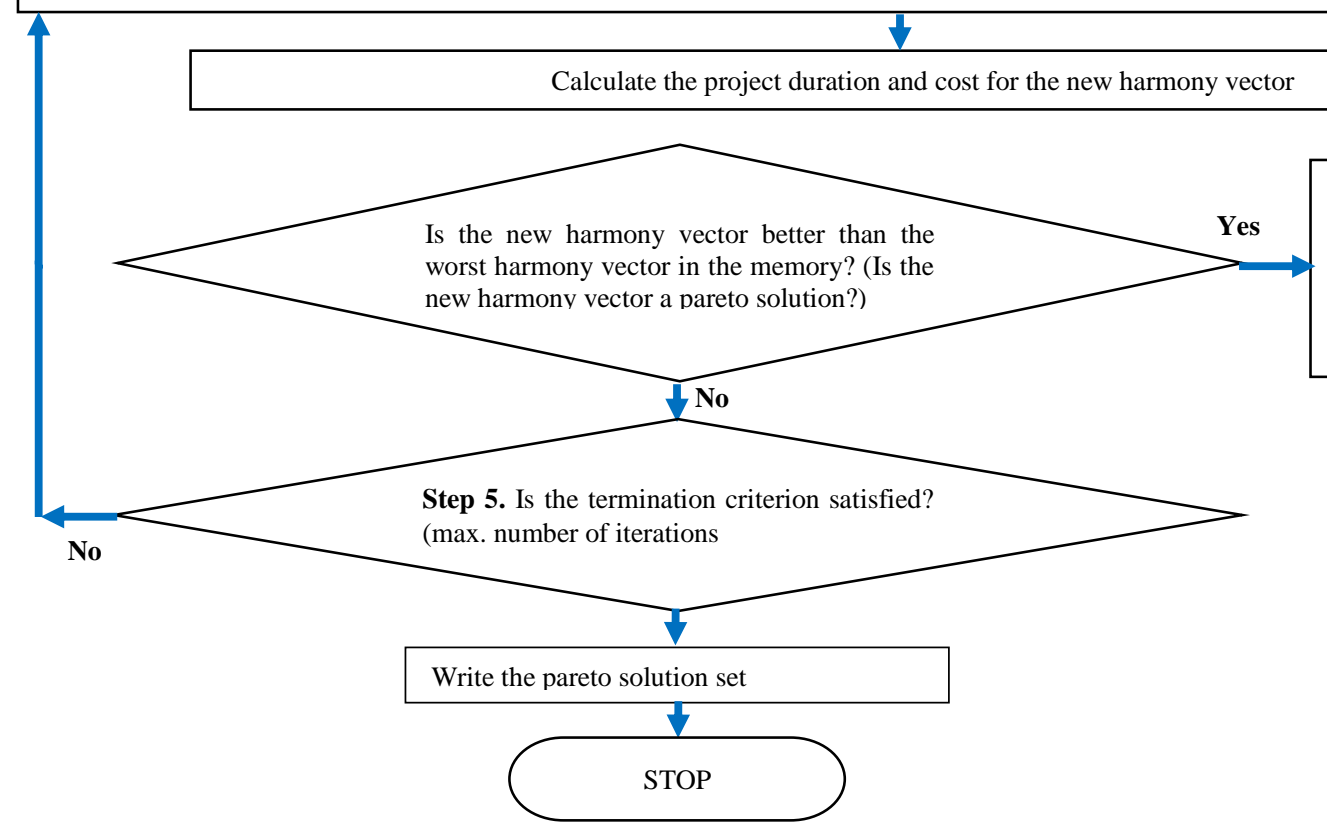

Step 4. Update of the harmony memory (The worst harmony vector is selected from the harmony memory and replaced with a newly created and better harmony vector)

In multi-objective optimization problems, if a candidate is better than another one, Candidate-1 is absolutely dominant to Candidate- 2 and in terms of both time and cost. Due to two-dominance preferences, the Pareto solution set (the most convenient solution set) is numbers of 1, 2 and 3 in Figure 4. 


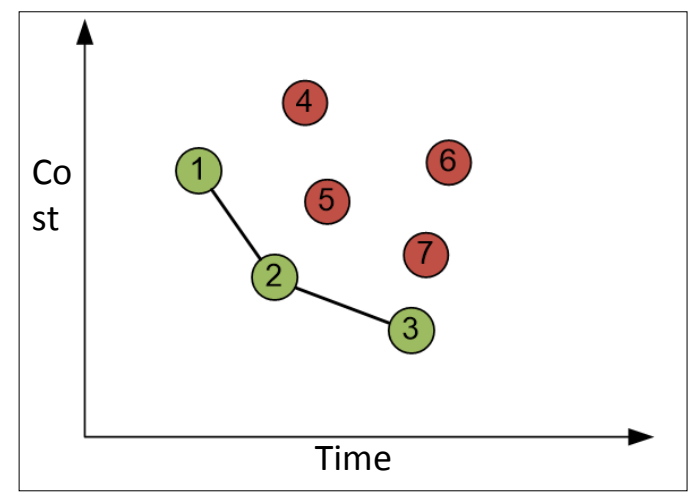

\section{Implementation of HS on construction project and a case study}

The prepared model, the inputs of the model, the results and findings retrieved from the model were evaluated based on excavation and construction project in Table 2. Firstly, the construction activities of the project were stated; the relationship among the activities was defined; CPM network of the project was drawn; the amount of the activities to be conducted was prepared. Afterwards, each activity in the project was investigated in terms of the techniques and different ways used during the construction. According to this, similar work items in the unit price analysis book of the Ministry of Environment and Urban Planning were extracted for each activity. The work items, which conducted the same activity yet displayed differences in terms of the rapidity of completion or unit price, have been detected by using similar work items. Finally, on the basis of the items related to the activities, it was aimed to obtain the most convenient time-cost pairs of the project through HS method.

\begin{tabular}{|c|c|c|c|c|}
\hline ID & Activity name & $\begin{array}{l}\text { Immediate } \\
\text { predecessor }\end{array}$ & $\begin{array}{l}\text { Approxima } \\
\text { te amount }\end{array}$ & $\begin{array}{l}\text { Alternative work items of activity } \\
\text { according to the unit price analysis book }\end{array}$ \\
\hline A & Excavation & - & $4000 \mathrm{~m}^{3}$ & $(15.010 / 3 \mathrm{~B}),(15.010 / 4 \mathrm{~B})$ \\
\hline B & Filling with Sealant & A & $180 \mathrm{~m}^{3}$ & $\begin{array}{c}(14.1714 / 1),(14.1717) \\
(15.140 / \text { iB-1) }\end{array}$ \\
\hline C & Laying lean concrete & B & $60 \mathrm{~m}^{3}$ & $(16.001)$ \\
\hline D & Main Water Insulation & C & $600 \mathrm{~m}^{2}$ & $(18.465 / 2),(18.467 / 2),(18.468 / 3)$ \\
\hline $\mathrm{E}$ & $\begin{array}{l}\text { Laying Insulation Screed } \\
\qquad(3.5 \mathrm{~cm})\end{array}$ & D & $600 \mathrm{~m}^{2}$ & (19.101/MK) \\
\hline $\mathrm{F}$ & $\begin{array}{l}\text { Building Foundation } \\
\text { Formwork } \\
\text { Preparing and Placing }\end{array}$ & $\mathrm{E}$ & $60 \mathrm{~m}^{2}$ & $(21.001 / 02),(21.016),(21.0172)$ \\
\hline G & $\begin{array}{c}\text { Foundation } \\
\text { Reinforcement }\end{array}$ & $E$ & 20 ton & (23.015) \\
\hline $\mathrm{H}$ & $\begin{array}{l}\text { Pouring Foundation } \\
\text { Concrete }\end{array}$ & $F, G$ & $360 \mathrm{~m}^{3}$ & $(16.059 / 1)$ \\
\hline
\end{tabular}


In the examined construction project, the number of teams is considered one at a minimum rate, and three at a maximum rate for each activity. The number of teams will be randomly selected for each work item between 1 and 3 range. The daily indirect cost of the construction area is determined as USD 22.5. The data related to selected work items are given in Table 3.

Table 3. The activities of the construction project. Source: Zalmai (2015).

\begin{tabular}{|c|c|c|c|c|c|}
\hline Activity & $\begin{array}{l}\text { Option } \\
\text { no }\end{array}$ & $\begin{array}{c}\text { Work item } \\
\text { no }\end{array}$ & Unit & $\begin{array}{l}\text { Unit cost } \\
\text { (USD) }\end{array}$ & $\begin{array}{c}\text { Average production } \\
\text { amount of the } \\
\text { team (unit/day) }\end{array}$ \\
\hline \multirow[t]{2}{*}{ Excavation } & 1 & $15.010 / 3 \mathrm{~B}$ & $\mathrm{~m}^{3}$ & 3.31 & 316.80 \\
\hline & 2 & $15.010 / 4 \mathrm{~B}$ & $\mathrm{~m}^{3}$ & 2.34 & 256.32 \\
\hline \multirow[t]{3}{*}{ Filling with sealant } & 1 & $14.1714 / 1$ & $\mathrm{~m}^{3}$ & 1.46 & 24.00 \\
\hline & 2 & 14.1717 & $\mathrm{~m}^{3}$ & 4.18 & 27.84 \\
\hline & 3 & 15.140/іB-1 & $\mathrm{m}^{3}$ & 2.10 & 16.08 \\
\hline Lean concrete & 1 & 16.001 & $\mathrm{~m}^{3}$ & 25.89 & 33.36 \\
\hline \multirow[t]{3}{*}{ Water insulation } & 1 & $18.465 / 2$ & $\mathrm{~m}^{2}$ & 6.29 & 68.64 \\
\hline & 2 & $18.467 / 2$ & $\mathrm{~m}^{2}$ & 7.40 & 79.92 \\
\hline & 3 & $18.468 / 3$ & $\mathrm{~m}^{2}$ & 5.45 & 60.00 \\
\hline Laying screed & 1 & 19.101 & $\mathrm{~m}^{2}$ & 4.19 & 30.80 \\
\hline \multirow[t]{3}{*}{ Building formwork } & 1 & $21.001 / 02$ & $\mathrm{~m}^{2}$ & 6.75 & 9.76 \\
\hline & 2 & 21.016 & $\mathrm{~m}^{2}$ & 13.40 & 5.36 \\
\hline & 3 & $21.017 / 2$ & $\mathrm{~m}^{2}$ & 7.50 & 4.00 \\
\hline Iron making & 1 & 23.015 & ton & 512.36 & 0.69 \\
\hline Pouring concrete & 1 & $16.059 / 1$ & $\mathrm{~m}^{3}$ & 24.38 & 79,92 \\
\hline
\end{tabular}

\section{Results and discussion}

In construction projects, the shortening of the project duration is taken into consideration due to the positive effect on costs. In contrast, accelerating the plant causes additional costs and can only reduce the total cost to a certain level. The analysis of the trade-off between time and cost in construction management is called time-cost trade-off optimization. However, existing commercial software and methods proposed can provide extremely limited solutions for solving the problem of time-cost cut-off. From this point, a man-hour account was made for each activity according to the performance of the workers based on the unit price analysis of the Ministry of Environment and Urbanization. In the man-hours calculation of an activity, firstly the team speeds of the corresponding work item were found, after which the average daily production amount of a team was calculated according to the team speeds of the work items. The calculated man-hours account and unit cost data of the project activities are entered as a program input, and the Pareto time-cost solution curves are obtained according to the analysis tables of the relevant exposures of the project activities.

Time-cost pairs are shown for the first and one-hundredth iteration in Figure 6. In the first iteration, the Pareto front includes only one-time-cost pair, shown in red. In the results of the one-hundredth iteration, Pareto front includes three time-cost pairs. As the number of iterations increases, better results are achieved, after $1000^{\text {th }}$ iteration the results are converged. Therefore, the number of iterations of the implementation project was chosen to be 1000 .
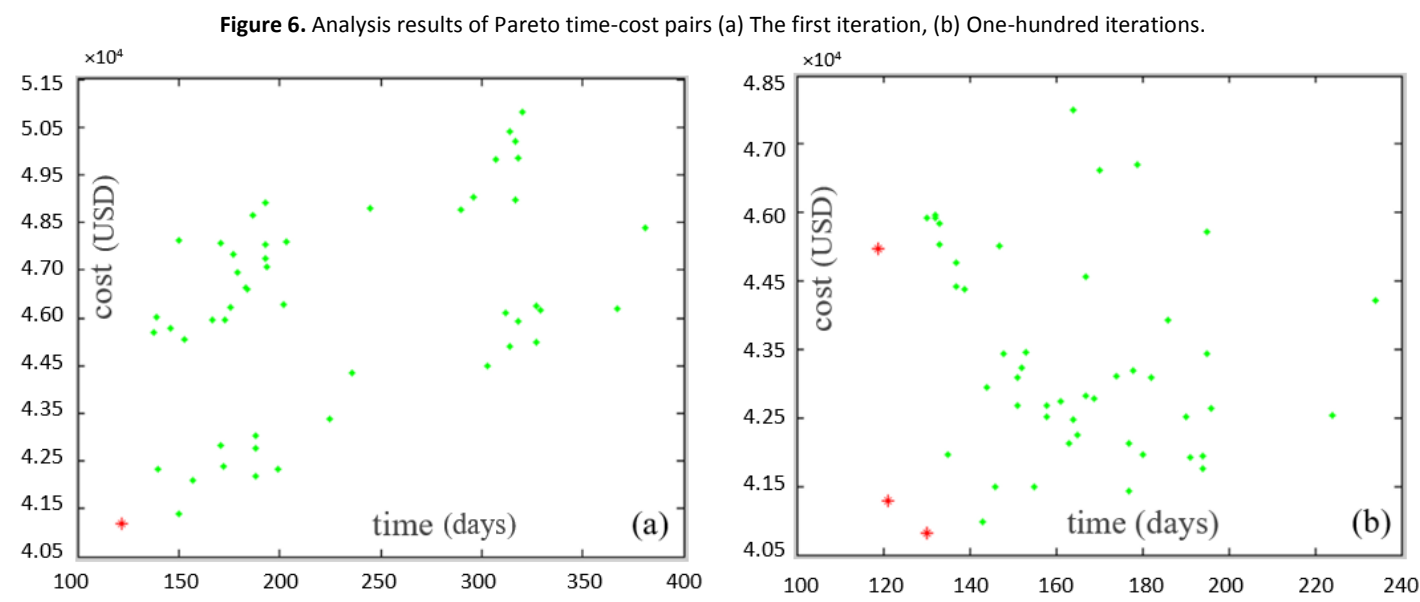
Figure 7 shows four different Pareto solutions shown in red for the application project, which is the essential construction work. For larger projects with a larger number of activities, the number of Pareto solutions is higher. Only four different optimum solutions could be obtained depending on the number of activities in the project and the number of alternative work items in the project and the small amount of activity.

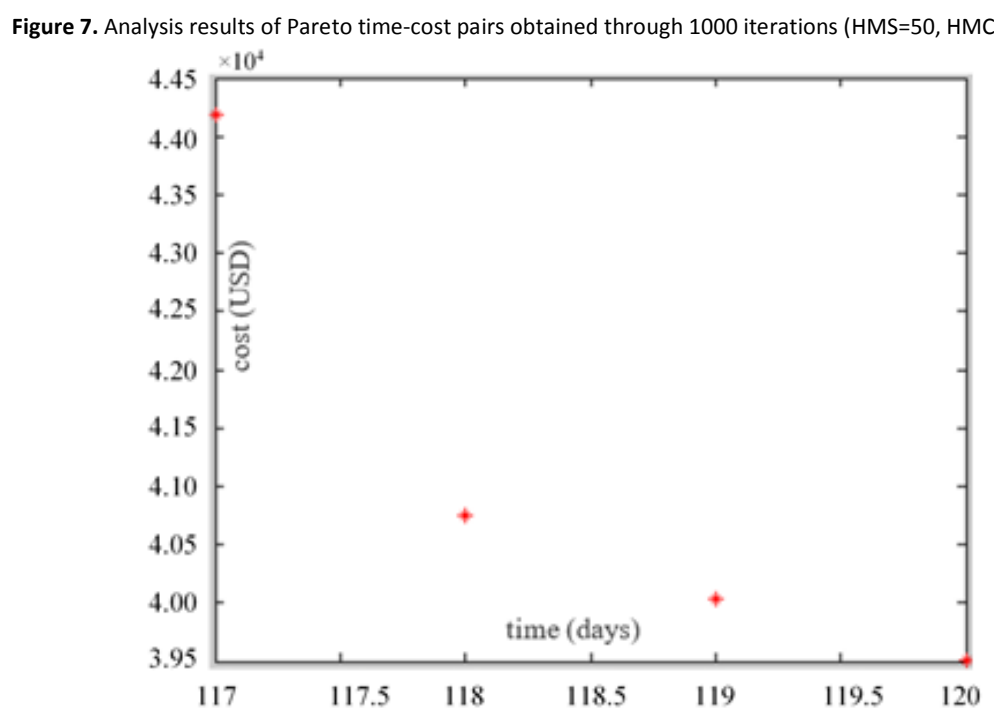

Table 4 displays the most convenient time-cost pairs to complete of the project according to different project duration or project cost restrictions. It is selected any solution based on time or cost restriction of the project. If time restriction is more important; and if the project has to be completed in 119 days, the most convenient solution is 119 days, USD $40.035,00$. All time-cost pairs before this solution point in the Table can be selected and are convenient solutions. However, the solutions coming after 119 days, USD 39.500,00 are not convenient solutions even though their cost may be less. This is because the duration of the project is more than 119 days.

Table 4. Pareto result of eight-activities for laying the groundwork through Harmony Analysis with 1000 iterations.

\begin{tabular}{|c|c|c|c|c|c|c|c|c|c|c|c|c|c|c|c|c|c|}
\hline \multicolumn{18}{|c|}{ The activities } \\
\hline & & \multicolumn{2}{|c|}{ Excavation } & \multicolumn{2}{|c|}{ Sealant } & \multicolumn{2}{|c|}{$\begin{array}{c}\text { Lean } \\
\text { concrete }\end{array}$} & \multicolumn{2}{|c|}{ Insulation } & \multicolumn{2}{|c|}{ Screed } & \multicolumn{2}{|c|}{ Formwork } & \multicolumn{2}{|c|}{ Iron } & \multicolumn{2}{|c|}{ Concrete } \\
\hline $\begin{array}{l}\text { Project } \\
\text { duration } \\
\text { (days) }\end{array}$ & $\begin{array}{c}\text { Project } \\
\text { cost } \\
\text { (USD) }\end{array}$ & $A^{*}$ & $\mathrm{~B}^{* *}$ & $A$ & $B$ & $A$ & B & $A$ & B & $A$ & B & A & B & $A$ & B & A & B \\
\hline 117 & 44.210 & 1 & 3 & 1 & 3 & 1 & 3 & 1 & 3 & 1 & 3 & 1 & 3 & 1 & 3 & 1 & 3 \\
\hline 118 & 40.712 & 2 & 3 & 1 & 3 & 1 & 3 & 2 & 3 & 1 & 3 & 1 & 3 & 1 & 3 & 1 & 3 \\
\hline 119 & 40.035 & 2 & 3 & 1 & 3 & 1 & 3 & 1 & 3 & 1 & 3 & 1 & 3 & 1 & 3 & 1 & 3 \\
\hline 120 & 39.500 & 2 & 3 & 1 & 3 & 1 & 3 & 3 & 3 & 1 & 3 & 1 & 3 & 1 & 3 & 1 & 3 \\
\hline
\end{tabular}

${ }^{*}$ A: Activity no, ${ }^{* *}$ B: Number of teams.

The most important problems in the construction sector, especially for employers and contractors, are project duration and cost. In other words, these two parameters change inversely proportional to each other. For this reason, it is aimed to reduce project cost as well as project duration in a multipurpose optimization environment. One of the most important factors affecting the project cost is the indirect costs incurred during the project although there is no direct contribution to the continuation of the project. Since many activities in construction projects are done with overtime or with different technology, the construction speeds of the activities and therefore the duration of the activities are changing. Also, the operating costs can also be changed as a result of changing the construction technique. Thus, in total time and total cost optimization, the combination problem, which is difficult to solve, arises. As a solution to this situation, the approximate solution can be reached quickly by using the metaheuristic methods.

In the present study, time-cost values that can be updated for each activity were obtained based on unit price analysis data. Afterward, multi-purpose time-cost optimization was carried out considering the team speeds and costs of different work items belonging to the activities. The prepared model was applied on a real construction project data 
and the results were obtained. Within the scope of the application project, four different solutions were obtained from the HS model. The time and the cost difference between these solutions is due to the alternative solutions or options of the three activities in the project (excavation, insulation and mold works). Among these activities, it was determined that the activity that affects the project cost the greatest is the excavation activity while the activity which affects the most during the period is the insulation activity. In order to obtain good results from the model, appropriate values of the model parameters have been investigated and proposed. The model has the feature that it can be adapted to other construction projects on the market. The duration of the activities was determined on the basis of the data of construction unit price analysis. In the study, different solutions are proposed for the implementation project considering the different construction applications of the activities and the obtained data are presented in a way that can be compared between the solutions. In the present approach, for each activity, without any comparison, one of the different application forms is selected, and single project duration and project cost are estimated accordingly. Therefore, the best solutions are ignored according to the importance of time or cost congestions. In the next research, it is aimed to develop a multi-purpose optimizing planning software that can be applied to the construction sector by expanding the content of the project.

\section{Acknowledgments}

The study was financially supported by the Istanbul University Scientific Research Projects Unit under project number 50827 (Istanbul, Turkey).

\section{References}

Albayrak, G. and Özdemir, I. (2018). Multimodal optimization for time-cost trade-off in construction projects using a novel hybrid method based on FA and PSO. Revista de la Construcción, 17, 304-318. DOI: 10.7764/RDLC.17.2.304.

Aminbakhsh, S. and Sonmez, R. (2016). Discrete particle swarm optimization method for the large-scale discrete time-cost trade-off problem. Expert Systems with Applications, 51, 177-185.

Ashuri, B. and Tavakolan, M. (2015). Shuffled Frog-Leaping Model for Solving Time Cost-Resource Optimization Problems in Construction Project Planning. Journal of Computing in Civil Engineering, 29(1), 04014026.

Chen, S. P. and Tsai, M. J. (2011). Time-cost trade-off analysis of project networks in fuzzy environments. European Journal of Operational Research, 212(2), 386-397.

De, P., Dunne, E. J., Ghosh, J. B. and Wells, C. E. (1997). Complexity of the Discrete Time-Cost Tradeoff Problem for Project Networks. Operations Research, 45(2), 302-306.

Feng, Ch. W., Lui, L. and Burns, A. (1997). Using genetic algorithms to solve construction time-cost trade-off problems. Journal of Computing in Civil Engineering, 11(3), 184-189.

Geem, Z.W., Kim, J.H. and Loganathan, G.V. (2001). A new heuristic optimization algorithm: harmony search. Simulation, 76(2), 60-68.

Geem, Z.W., Lee, K.S. and Park, Y. (2005). Application of harmony search to vehicle routing. American Journal of Applied Sciences, 2 (12), $1552-1557$.

Geem, Z. W. (2008). Novel Derivative of Harmony Search Algorithm for Discrete Design Variables. Applied Mathematics and Computation, 199(1), 223-230.

Geem, Z. W. (2010a). Recent advances in harmony search algorithm. Springer ISSN 1860-949X. USA

Geem, Z.W. (2010b). Multiobjective optimization of time-cost trade-off using harmony search. Journal of Construction Engineering and Management, ASCE, 136(6), 711-16.

Gil-Lopez, S., Del Ser, J. and Olabarrieta, I. (2009). A novel heuristic algorithm for multiuser detection in synchronous CDMA wireless sensor networks. Ultra-modern telecommunications \& workshops, 1 - 6. 10.1109/ICUMT.2009.5345659.

He, Z., He, H., Liu, R., and Wang, N. (2017). Variable neighbourhood search and tabu search for a discrete time/cost trade-off problem to minimize the maximal cash flow gap. Computers and Operations Research, 78, 564-577.

Hegazy, T. (1999). Optimization of construction time-cost trade-off analysis using genetic algorithms. Canadian Journal of Civil Engineering, 26, 685697.

Hendrickson, C., and Au, T. (1989). Project management for construction. Prentice Hall, Englewood Cliffs, N.J., USA.

Jian-Hong, S., Li-Dan, L., Xiao-Ning, S. and Xiao-Rong Z. (2017). time-cost trade-off of project based on the improved harmony search algorithm. Journal of Engineering Management, 02, TU721.

Kelley, J. E. (1961). Critical-Path Planning and Scheduling: Mathematical Basis. Operations Research, 9(3), 296-320

Lee, K.S. and Geem, Z.W. (2005). A new meta-heuristic algorithm for continuous engineering optimization: harmony search theory and practice. Computer Methods in Applied Mechanics and Engineering, 194, 3902-3933. 
Mahdavi, M., Fesanghary, M. and Damangir, E. (2007). An improved harmony search algorithm for solving optimization problems. Appl. Math. Comput., 188, 1567-1579.

Manjarres, D., Landa-Torres, I., Gil-Lopez, S., Del Ser, J., Bilbao, M.N., Salcedo-Sanz, S. and Geem, Z.W. (2013). A survey on applications of the harmony search algorithm. Engineering Applications of Artificial Intelligence, 26(8), 1818-1831.

Orman, M.G.H. and Mahdavi, M. (2008). Global-best harmony search. Appl. Math. Comput., 198, 643-656.

Peraza, C., Valdez, F. and Castillo, O. (2015). A Harmony Search Algorithm Comparison with Genetic Algorithms. Springer International Publishing Switzerland. DOI: 10.1007/978-3-319-10960.

Praščević, N. And Praščević, Ž. (2014). Application of particle swarms for project time-cost optimization, Građevinar, 66(12), $1097-1107$.

Salem, A. M. and Elmaghraby, S. E. (1994). Optimal linear approximation in Project compression. IIE Transactions (Institute of Industrial Engineers), 16(4), 339-347.

Siemens, N. (1971). A simple CPM time-cost tradeoff algorithm. Management Science, 17(6), 354-363.

Sonmez, R. and Bettemir, Ö.H. (2012). A hybrid genetic algorithm for the discrete time-cost trade off problem. Expert Systems with Applications, 39, $11428-11434$

Stevens, James D. (1990). Techniques for construction network scheduling. (International ed.). New York, USA: McGraw-Hill Book Co.

Stützle, T and Dorigo, M. (2004). Ant colony optimization. London, England: A Bradford book, The MIT Press Cambridge.

Tareghian, H. R. and Taheri, H. (2006). An application of randomized minimum cut to the project time/cost tradeoff problem. Applied Mathematics and Computation, 173(2), 1200-1207.

Tran, D. H. and Long, L. D. (2018). Project scheduling with time, cost and risk trade-off using adaptive multiple objective differential evolution. Engineering, Construction and Architectural Management, 25(5), 623-638

Wolpert, D.H. and Macready, W.G. (1997). No free lunch theorems for optimization. IEEE Trans. Evol. Comput., 1(1), 67-82.

Yang, X. Sh. (2010). Engineering optimization: an introduction with metaheuristic applications. (1st ed.). Hoboken, USA: John Wiley and Sons Ltd.

Zalmai, M. L. (2015). A performance model development in construction projects using harmony search approach (Master's thesis). Retrieved from Turkey Council of Higher Education Thesis Center Database. (Accession No. 411484) 